\title{
Regioselective Asymmetric Alkynylation of N-Alkyl Pyridiniums
}

\author{
Thiago A. Grigolo, Ariana R. Subhit, and Joel M. Smith* \\ Department of Chemistry and Biochemistry, Florida State University, 95 Chieftan Way, Tallahassee, FL 32306 \\ Supporting Information Placeholder
}

\begin{abstract}
Disclosed in this communication is a novel asymmetric addition of alkynyl nucleophiles to $N$-alkyl pyridinium electrophiles. The coupling is effected under mild and simple reaction conditions, affording dihydropyridine products with complete regiochemical and stereochemical control. In addition to several manipulations of the dihyropyridine products, the utility of this transformation is demonstrated through a concise, dearomative, and asymmetric synthesis of (+)-lupinine, a natural acetylcholine esterase inhibitor.
\end{abstract}

Alkaloid natural products have a rich history in medicine, ${ }^{1,2}$ thus fortuitously inspiring innovation and invention by synthetic chemists for decades. ${ }^{3}$ In turn, the piperidine heterocycle, a common moiety in bioactive alkaloids and rationally designed drugs $^{4}$ has demanded creative new strategies for its construction for many years. ${ }^{5-9}$ Moreover, the asymmetric construction of substituted congeners of this important heterocycle has been of the utmost importance in the synthetic pursuit of complex and medicinally relevant molecular targets. ${ }^{10}$

Notable biologically active targets that contain multiply-substituted piperidines are depicted in Figure 1A. For example, the bisquinolizidine alkaloids related to (-)-neothiobinupharidine (2) have shown unique inhibition of the NF- $\mathrm{kB}$ signaling pathway ${ }^{11}$ and tangutorine (3) has displayed noteworthy anticancer activity. ${ }^{12}$ Recently, the akuammiline alkaloid 2(S)-cathafoline (4) has shown remarkable inhibition of $\mathrm{Ca}^{+2}$-ion channels ${ }^{13}$ while (+)-lupinine (1) has been shown to inhibit acetylcholine esterase. ${ }^{14}$ Beyond their impressive biological profiles, each of these synthetic targets contains at least one of its stereogenic centers adjacent to the nitrogen atom of the piperidine heterocycle (See starred atoms, Figure 1A). While considering this salient structural feature, we aimed to develop a unified approach that would be general for building various piperidines thus allowing concise and asymmetric access to these privileged bioactive substances.

Recently, our research group became interested in the synthesis of biologically active alkaloids through the dearomatization of heterocyclic aromatic starting materials. ${ }^{15}$ For example, (+)-lupinine (1) was envisioned to arise from dihydropyridine 5 , which would be derived from the dearomative coupling of alkyne 7 and pyridinium 6 (See Figure 1B). ${ }^{16-23}$ One example of this type of asymmetric dearomative alkynylation was demonstrated by Charette in 2001 exploiting a chiral iminoyl group to activate the pyridine (8) electrophile. ${ }^{24}$ Regioselective addition of the alkynyl Grignard reagent, as directed by the activating group, provided dihydropyridine 9 . While innovative,
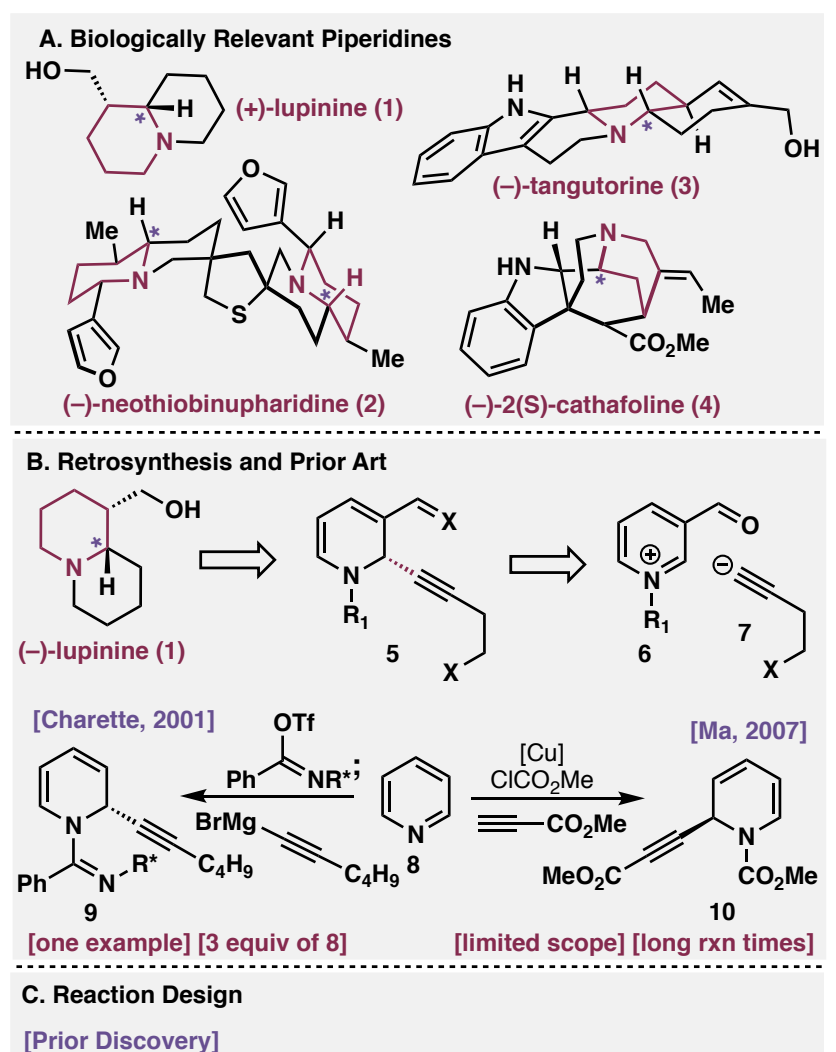

[Prior Discovery]

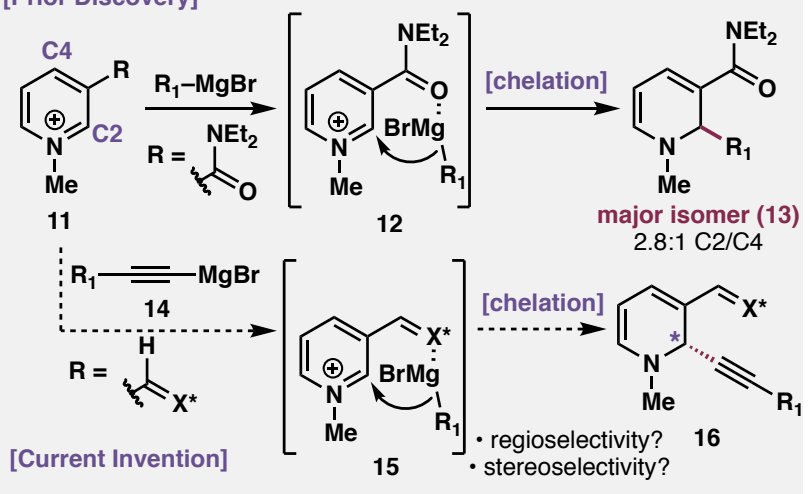

- New asymmetric alkynylation of substituted pyridiniums

- Useful avenue for asymmetric access to alkaloids and drugs

Figure 1. (A) Representative and important piperidines and tetrahydropyridines. (B) Previously observed regioselective pyridinium dearomatizaton driven by chelation, and proposed chelation-driven asymmetric alkynylation.

superstoichiometric amounts of the pyridine heterocycle $(\mathbf{8})$ had to be employed in this protocol, limiting its broader utility. Years later, Ma and coworkers demonstrated a similar transformation using a chiral $\mathrm{Cu}$ catalyst and acylated pyridiniums for enantioselective dearomative alkynylation (see 13). ${ }^{25}$ This transformation was also remarkable, but only pyridine $(\mathbf{8})$ was 
used as a substrate, and only ynone and ynoate nucleophiles provided high enantioselectivities. Shortly after this, another single example of an enantioselective alkynylation of an acylated pyridine was also demonstrated by Arndtsen. ${ }^{26}$ Furthermore, while much work has been done activating pyridines and other aromatic azacycles ${ }^{27,28}$ via acylation, including these aforementioned examples, selective additions to $N$-alkyl pyridiniums have lagged behind, ${ }^{29-32}$ despite their potential to provide more robust and strategic access to piperidine heterocycles with higher regio- and stereocontrol (vide infra).

Prior work in our group established a working model for the innate regioselectivity for the attack of Grignard nucleophiles on substituted pyridiniums. ${ }^{[15]}$ In one scenario (See Figure 1C), an amide substituent provided for a regioselective nucleophilic addition at $\mathrm{C} 2$ that resulted in the conversion of pyridinium $\mathbf{1 1}$ to dihydropyridine 13. Seeing that it was likely amide chelation of the organometallic that drove this regioselective preference (see intermediate 12), it was thought that substituting the amide with a simple chiral guide $\left(\mathbf{X}^{*}\right.$, see $\left.\mathbf{1 5}\right)$ would both control the regiochemistry and stereochemistry of the dearomative addition (see 16). Regioselective preference was likely to be enhanced by using alkynylmagnesium nucleophiles (e.g. 14), which show preferential pyridinium addition at $\mathrm{C} 2$ and $\mathrm{C} 6$. It should be noted that, while alkynyl nucleophiles have been added into pyridiniums previously, there are no examples of highly regioselective and stereoselective additions to substituted pyridiniums. Overall, overcoming these obstacles in selectivity would add value to employing dearomative strategies and tactics toward the asymmetric synthesis of polysubstituted piperidine motifs.

Initially, exploration of the desired alkynylation reaction was inspired by Koga's work on addition to unsaturated aldehydes from several decades ago (See Table 1). ${ }^{[33]}$ Following simple condensation between $L$-tert-leucine tert-butyl ester and 3 -formylpyridine to form 17 , chemoselective methylation and

Table 1

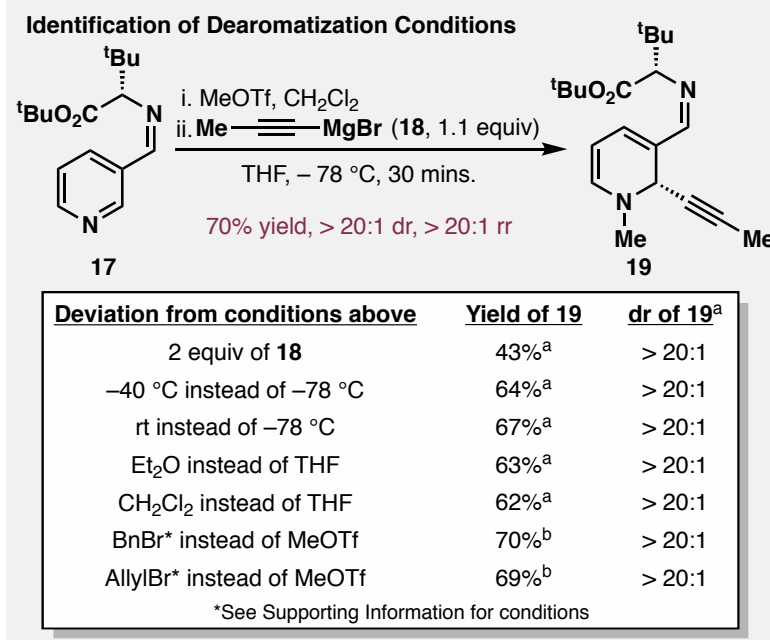

Table 1. Reaction optimization studies. aDetermined by ${ }^{1} \mathrm{H}$ NMR analysis of the crude mixture with an internal standard. blsolated yield.

treatment with propynylmagnesium bromide (18) resulted in the selective formation of dihydropyridine $\mathbf{1 9}$ in $70 \%$ yield. This addition occurred with full stereoselectivity $(>20: 1 \mathrm{dr})$ and regioselectivity for $\mathrm{C} 2(>20: 1 \mathrm{rr})$. The regioselectivity and stereoselectivity is noteworthy as the regioselective asymmetric addition of nucleophiles at $\mathrm{C} 2$ to pyridiniums with electronwithdrawing groups at $\mathrm{C} 3$ has not been reported. ${ }^{[34-37]}$ Altering

\section{Scheme 1}
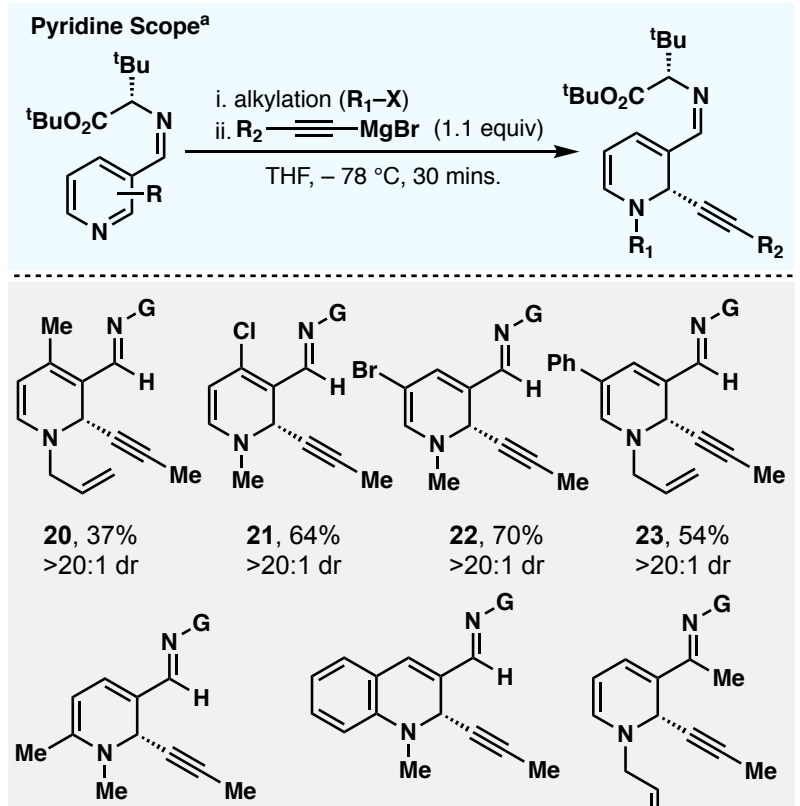<smiles>CC#C[C@H]1C(/C=N/C)=Cc2ccccc2N1C</smiles>

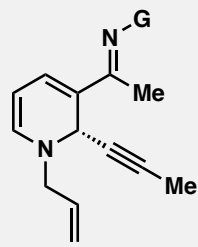

24, $50 \%$

$$
>20: 1 \mathrm{dr}
$$
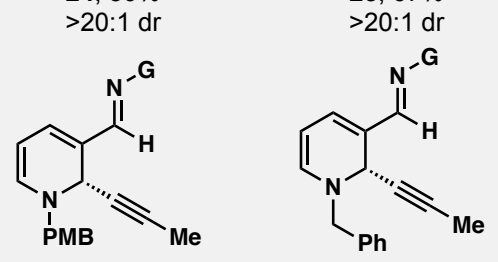

26, $43 \%$

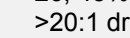

$$
\begin{aligned}
& 27,65 \% \\
& >20: 1 \mathrm{dr}
\end{aligned}
$$<smiles>C/N=C/C1=CC=CN(Cc2ccccc2)[C@H]1C#CCCCl</smiles>

28, $70 \%$ $>20: 1 d r$

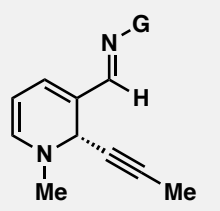

$29,90 \%$ b $>20: 1 \mathrm{dr}$

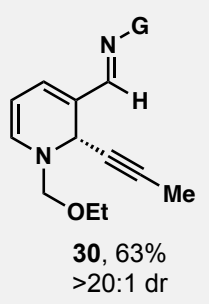

$19,70 \%$ $>20: 1 \mathrm{dr}$

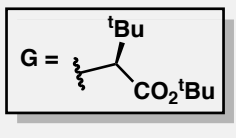

Scheme 1. Scope of alkynylation of various pyridines. aisolated yields (Diastereoselectivity determined by analysis of crude ${ }^{1} \mathrm{H}$ NMR spectrum). ${ }^{\mathrm{b}} 6.5: 1$ ratio of imine to corresponding aldehyde.

the temperature $\left(-40^{\circ} \mathrm{C}\right.$ or $\left.\mathrm{rt}\right)$ had little effect on the selectivity, but resulted in slightly reduced yields. Changing the solvent from THF to either $\mathrm{CH}_{2} \mathrm{Cl}_{2}$ or $\mathrm{Et}_{2} \mathrm{O}$ also resulted in only a minor effect on the yield. In the interest of using a removable nitrogen substituent, activation of the pyridine 17 with either benzyl bromide or allyl bromide (See Supporting Information for experimental details) followed by propynylmagnesium bromide resulted in comparable yields.

With optimized conditions in hand, we embarked on exploring the asymmetric alkynylation of various substituted pyridine starting materials (Scheme 1). Following alkylation with either allyl bromide or methyl triflate, pyridinium intermdiates with substitution at the 4,5 , and 6 positions were successfully converted to the corresponding alkynylated dihydropyridines. Furthermore, chloride (21), bromide (22), aryl (23), and alkyl $(\mathbf{2 0}, \mathbf{2 4})$ substitution were all tolerated under the reaction conditions with adducts isolated in $37-70 \%$ yields. A 
dihydroquinoline product (25) was also afforded following activation via methylation with MeOTf and treatment with propynylmagnesium bromide. In addition, dihydropyridine 26, derived from 3-acetylpyridine was also produced with this method demonstrating that aldimines are not the only competent functionality for directing the desired addition. It should be noted that, despite the substitution pattern for any of these substrates, only one stereoisomer and one regioisomer was observed in each case.

Next, the activating group was further evaluated to understand its effect on the alkynylation reaction. Having established that methyl (19), benzyl (28,29), and allyl (31) were all competent activating groups in the initial reaction screening, it was also determined that $p$-methoxybenzyl as well as methoxyethyl were also competent $N$-activating groups. The alkynylation of these pyridinium intermediates provided 27 in $65 \%$ yield and 30 in $70 \%$ yield, each with full regioselectivity and stereoselectivity. Activation of the pyridine nitrogen of $\mathbf{1 7}$ via acylation was also briefly explored, but upon addition of either organocopper or organomagnesium acetylides, complex mixtures of regioisomers, diastereomers, and rotamers were observed, in agreement with previous work on alkynylation of substituted systems. ${ }^{35-38}$

Following the investigation of variously substituted pyridines, the scope of alkyne addition was evaluated using pyridine $\mathbf{1 7}$ as a model substrate (Scheme 2). Upon treatment of $\mathbf{1 7}$ with allyl bromide, the resultant pyridinium was then treated with a variety of alkynyl Grignard reagents to afford variously substituted dihydropyridine adducts in 30 minutes at $-78^{\circ} \mathrm{C}$. Alkynyl nucleophiles bearing alkyl (31,37), aryl (33), silyl (34), and alkoxy (35) substituents were all competent in this reaction giving synthetically useful yields with complete regio- and stereochemical control. In addition, ethynylmagnesium bromide was used as a nucleophile to selectively give adduct 32 in 75\% yield. Alkynes bearing propargylic ethers ( 38 and $\mathbf{3 9}$ ) and a homopropargylic chloride (36) also gave usefully functionalized products under this reactivity manifold, allowing for further synthetic manipulation following the dearomatization (vide infra). Aliphatic and aromatic heterocyclic alkynes also performed well yielding dihydropyridine adducts containing indole (40), pyridine (43), quinoline (44), and pyrrolidine (45) rings. It is worth noting that no epimerization was observed in adduct $\mathbf{4 5}$, as only one diastereomer was observed in the crude reaction mixture. Adducts with important isosteres ${ }^{39}$ like a cyclopropane and chemical reporter groups like a diyne ${ }^{40}$ also were incorporated into products $\mathbf{4 1}$ and $\mathbf{4 2}$ in $49 \%$ and $48 \%$ yield, respectively.

A stereochemical model for this asymmetric alkynylation reaction is depicted in Scheme 3A. Following activation of a pyridine 17 with allyl bromide to form an intermediate pyridinium bromide, the alkynyl Grignard $\mathbf{4 6}$ was introduced at -78 ${ }^{\circ} \mathrm{C}$. According to reactivity previously described by Koga for the addition to unsaturated imines, chelation of the magnesium center by the imino ester guides the alkynyl nucleophile to the $\mathrm{C} 2$ position (See intermediate 47). ${ }^{33}$ The tert-butyl group putatively blocks the top face of the pyridinium allowing for the alkyne nucleophile to approach from the opposite side, providing for high stereocontrol. In addition to the exquisite stereocontrol that is observed in this transformation, the absolute regioselectivity can be attributed both to the chelation by the imino ester as well as the preference for alkynes to add at the "harder" 2 position versus the 4 position of the pyridinium. ${ }^{29}$ Further evidence for this regioselective and stereoselective chemical model was confirmed by X-ray analysis of $\mathbf{3 4}$ which shows addition of the alkynyl nucleophile opposite of the bulky tert-butyl side chain to give the expected $\mathrm{C} 2$ stereochemical outcome. At this time, however, solvent effects on the transition state of the addition cannot be completely ruled out, as this has been crucial in the success of other asymmetric dearomatizations. ${ }^{41}$

The dihydropyridines forged from these asymmetric dearomatizations can be manipulated in variety of ways, as shown in Scheme 3B. Following cleavage of the chiral guide

\section{Scheme 2}

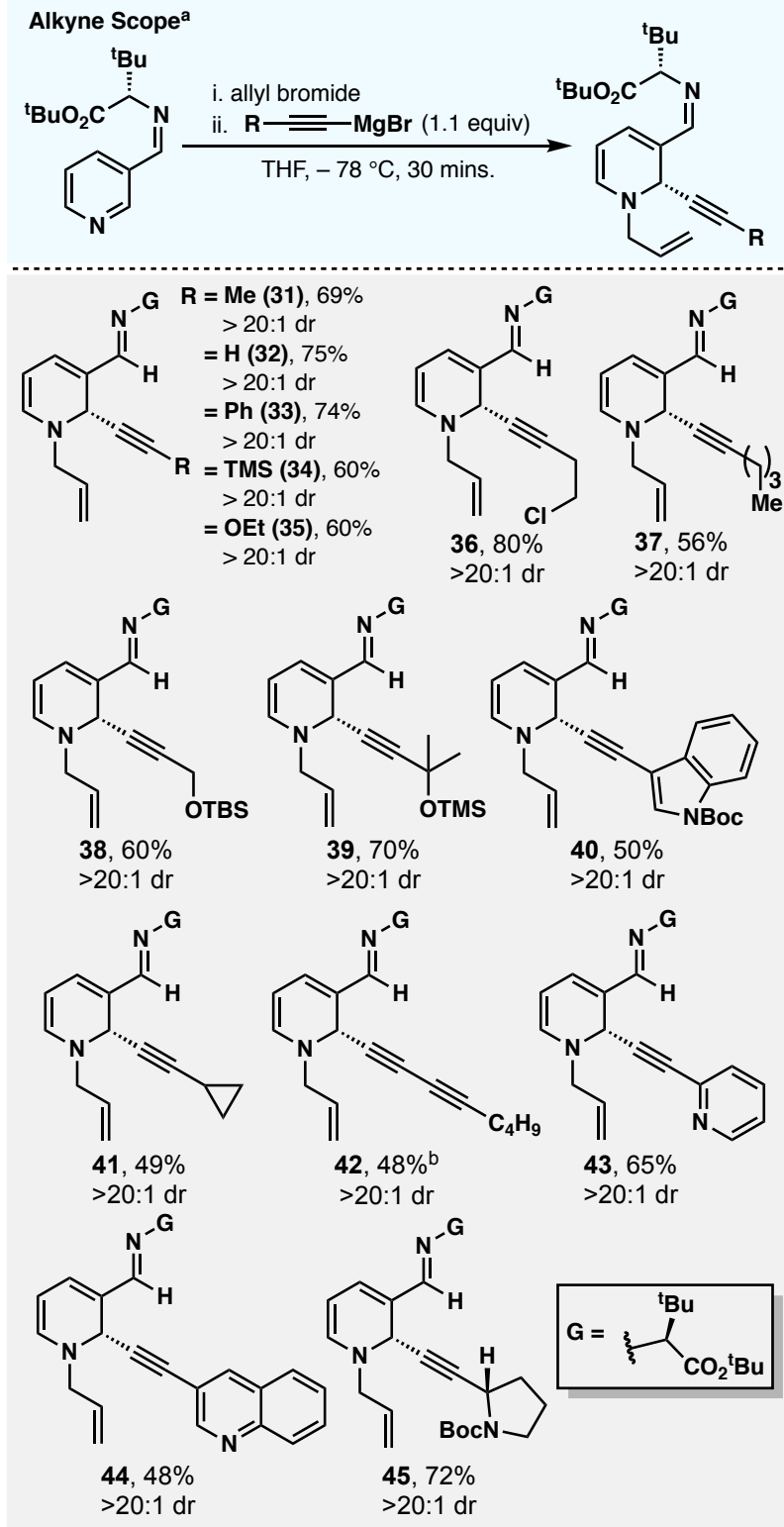

Scheme 2. Scope of alkyne additions to pyridine 17. aisolated yields (Diastereoselectivity determined by analysis of crude ${ }^{1} \mathrm{H}$ NMR spectrum). ${ }^{\mathrm{b}} 3.7: 1$ ratio of imine to corresponding aldehyde.

under treatment with basic alumina (See Supporting Information), aldehyde $48(\mathrm{R}=\mathrm{H}$ or $\mathrm{Me})$ can be converted to various products. Horner-Wadsworth-Emmons olefination at elevated temperature an provided ester $\mathbf{4 9}$, while activation of $\mathbf{4 8}$ with TIPSOTf in MeCN followed by TBAF treatment provided Mannich product 50 in 50\% yield. ${ }^{42} \mathrm{~A} \mathrm{Cu}$-catalyzed alkyne-azide "click" reaction with benzyl azide provided $\mathbf{5 1}$ in modest 
yield. ${ }^{43}$ It is anticipated that each of these modifications both to the periphery and the core of the alkynyl dihydropyridines will be instrumental in future dearomative synthetic endeavors.

Lastly, as the synthesis of alkaloid natural products was the original inspiration and impetus for this work, a concise synthesis of (+)-lupinine was accomplished (Scheme 3C). Starting from pyridine 17, activation with allyl bromide and selective alkynylation provided a mixture of aldehyde $\mathbf{5 3}$ and the corresponding imine in a $1: 2$ ratio and $86 \%$ overall yield. This ratio was the result of prolonged exposure of the product mixture to

Scheme 3

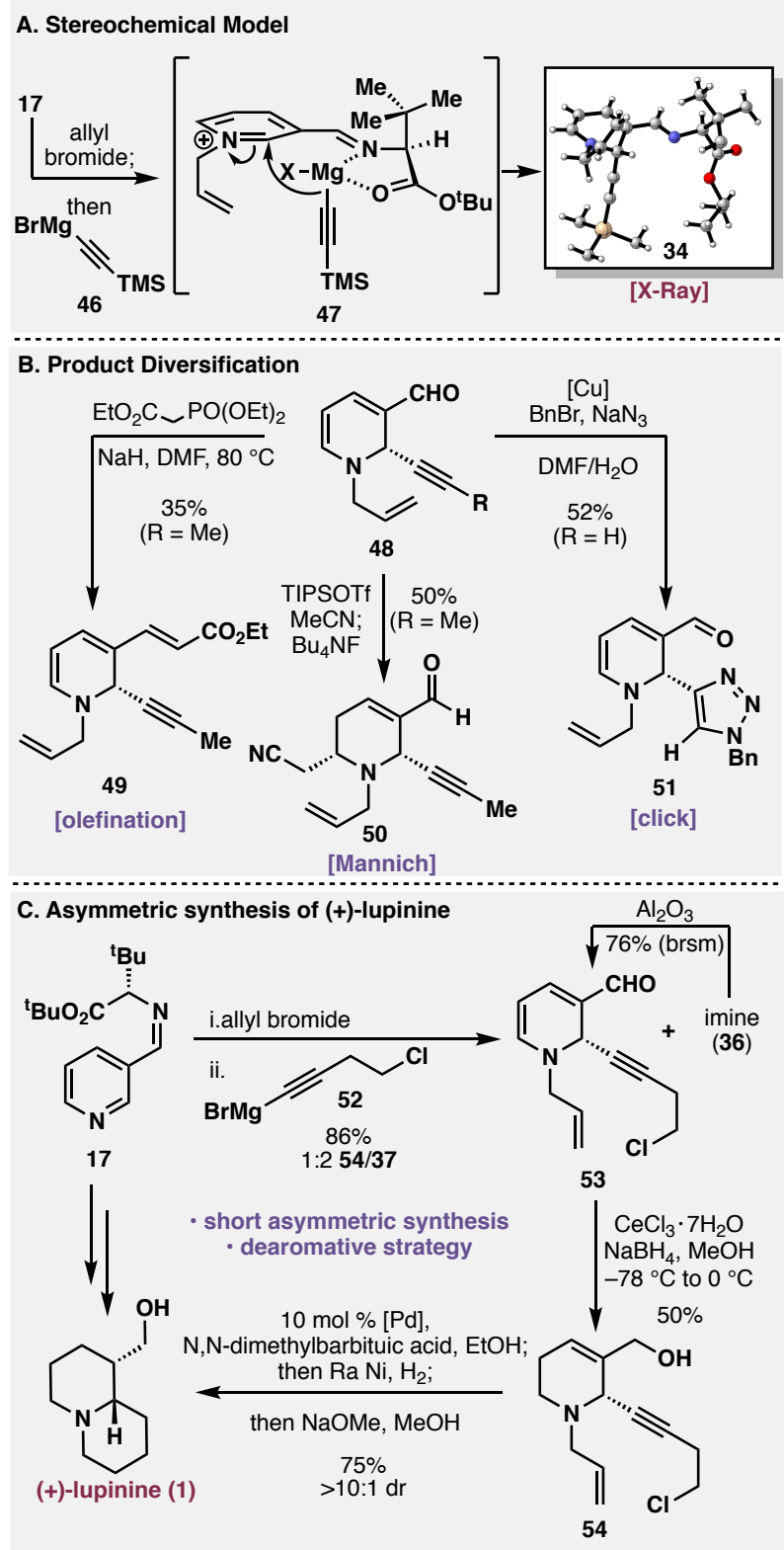

Scheme 3. (A) Model of asymmetric induction by chiral guide. (B) Diversification of dihydropyridine adduct. (C) Concise enantioselective total synthesis of (+)-lupinine.

basic alumina during the purification (See Supporting Information for details). Conveniently, imine 36 could by hydrolyzed to aldehyde $\mathbf{5 3}$ by further exposure to basic alumina. Then, reduction of dihydropyridine $\mathbf{5 3}$ under Luche conditions provided allylic alcohol 54 in 50\% yield. This intermediate was then deallylated under Pd catalysis, subjected to hydrogenation with Raney $\mathrm{Ni}$, and then cyclized under basic conditions in one pot to provide (+)-lupinine (1) in a 75\% yield and a $>10: 1$ diastereomeric ratio with its epimer epilupinine. ${ }^{44}$

In conclusion, a new asymmetric platform for the regioselective and stereoselective dearomatization of substituted pyridines has been achieved. In addition to having a broad scope and functional group tolerance, this transformation is useful for synthesizing a variety of dihydropyridines that can be broadly useful for the asymmetric synthesis of various azaheterocyclic building blocks. Furthermore, the implementation of this method in total synthesis was demonstrated through the concise asymmetric construction of the bicyclic alkaloid (+)-lupinine (1). The success of this synthesis served as a test for the implementation of this stereoselective and redox-economic dearomative approach to the synthesis of bioactive alkaloids. It is anticipated that further synthetic applications expanding upon this dearomative retrosynthetic analysis will be reported by our research group in due course.

\section{ASSOCIATED CONTENT}

\section{Supporting Information}

The Supporting Information is available free of charge on the ACS Publications website.

Supporting Information (PDF)

Crystallographic Information (CIF)

\section{AUTHOR INFORMATION}

\section{Corresponding Author}

* Email: smith@chem.fsu.edu

Notes

The authors declare no competing financial interest.

\section{ACKNOWLEDGMENT}

Financial support provided by Florida State University. We thank Xinsong Lin for assistance with X-ray data collection and structure determination. We thank Prof. James H. Frederich for helpful discussions.

\section{REFERENCES}

Corey, E. J.; Czakó, B.; Kürti, L. Molecules and Medicine; Wiley: Hoboken, NJ, USA, 2007.

Nicolaou, K. C.; Montagnon, T. Molecules That Changed the World; Wiley-VCH Verlag: Hoboken, NJ, USA, 2008.

Crossley, S. W. M.; Shenvi, R. A. A Longitudinal Study of Alkaloid Synthesis Reveals Functional Group Interconversions as Bad Actors. Chem. Rev. 2015, 115 (17), 9465-9531. https://doi.org/10.1021/acs.chemrev.5b00154.

Vitaku, E.; Smith, D. T.; Njardarson, J. T. Analysis of the Structural Diversity, Substitution Patterns, and Frequency of Nitrogen Heterocycles among U.S. FDA Approved Pharmaceuticals. J. Med. Chem. 2014, 57 (24), 10257-10274. https://doi.org/10.1021/jm501100b.

Laschat, S.; Dickner, T. Stereoselective Synthesis of Piperidines. Synthesis (Stuttg). 2000, 2000 (13), 1781-1813.

Srivastava, N.; Macha, L.; Ha, H.-J. Stereoselective Synthesis of 2,6-Disubstituted Piperidine Alkaloids. Org. Biomol. Chem. 2020, $18 \quad$ (29), 5493-5512. https://doi.org/10.1039/D0OB00918K.

7) Bari, A.; Iqbal, A.; Khan, Z. A.; Shahzad, S. A.; Yar, M. Synthetic Approaches toward Piperidine Related Structures: A Review. Synth. Commun. 2020, 50 (17), 2572-2589. https://doi.org/10.1080/00397911.2020.1776878. 

Kong, K.; Wood, J. L. Synthetic Studies toward the Citrinadins: Enantioselective Preparation of an Advanced Spirooxindole Intermediate. Tetrahedron 2014, 70, 4089.

(9) Bates, R. W ; Ko, W ; Barát, V. The Endo-Aza-Michael Addition in the Synthesis of Piperidines and Pyrrolidines. Org. Biomol. Chem. 2020, 18 (5), 810-829. https://doi.org/10.1039/C9OB02388G.

(10) Buffat, M. G. P. Synthesis of Piperidines. Tetrahedron 2004, 60 (8), $1701-1729$ https://doi.org/https://doi.org/10.1016/j.tet.2003.11.043.

(11) Ozer, J.; Eisner, N.; Ostrozhenkova, E.; Bacher, A.; Eisenreich, W.; Benharroch, D.; Golan-Goldhirsh, A.; Gopas, J. Nuphar Lutea Thioalkaloids Inhibit the Nuclear Factor KappaB Pathway, Potentiate Apoptosis and Are Synergistic with Cisplatin and Etoposide. Cancer Biol. Ther. 2009, 8 (19), 1860-1868. https://doi.org/10.4161/cbt.8.19.9567.

(12) Liu, B. P. L.; Chong, E. Y. Y.; Cheung, F. W. K.; Duan, J.-A.; Che, C.-T.; Liu, W. K. Tangutorine Induces P21 Expression and Abnormal Mitosis in Human Colon Cancer HT-29 Cells. Biochem. Pharmacol. 2005, 70 (2), 287-299. https://doi.org/https://doi.org/10.1016/j.bcp.2005.04.024.

(13) Kearney, S. E.; Zahoránszky-Kőhalmi, G.; Brimacombe, K. R.; Henderson, M. J.; Lynch, C.; Zhao, T.; Wan, K. K.; Itkin, Z.; Dillon, C.; Shen, M.; Cheff, D. M.; Lee, T. D.; Bougie, D.; Cheng, K.; Coussens, N. P.; Dorjsuren, D.; Eastman, R. T.; Huang, R.; Iannotti, M. J.; Karavadhi, S.; Klumpp-Thomas, C.; Roth, J. S.; Sakamuru, S.; Sun, W.; Titus, S. A.; Yasgar, A.; Zhang, Y.-Q.; Zhao, J.; Andrade, R. B.; Brown, M. K.; Burns, N. Z.; Cha, J. K.; Mevers, E. E.; Clardy, J.; Clement, J. A.; Crooks, P. A.; Cuny, G. D.; Ganor, J.; Moreno, J.; Morrill, L. A.; Picazo, E.; Susick, R. B.; Garg, N. K.; Goess, B. C.; Grossman, R. B.; Hughes, C. C.; Johnston, J. N.; Joullie, M. M.; Kinghorn, A. D.; Kingston, D. G. I.; Krische, M. J.; Kwon, O.; Maimone, T. J.; Majumdar, S.; Maloney, K. N.; Mohamed, E.; Murphy, B. T.; Nagorny, P.; Olson, D. E.; Overman, L. E.; Brown, L. E.; Snyder, J. K.; Porco, J. A.; Rivas, F.; Ross, S. A.; Sarpong, R.; Sharma, I.; Shaw, J. T.; Xu, Z.; Shen, B.; Shi, W.; Stephenson, C. R. J.; Verano, A. L.; Tan, D. S.; Tang, Y.; Taylor, R. E.; Thomson, R. J.; Vosburg, D. A.; Wu, J.; Wuest, W. M.; Zakarian, A.; Zhang, Y.; Ren, T.; Zuo, Z.; Inglese, J.; Michael, S.; Simeonov, A.; Zheng, W.; Shinn, P.; Jadhav, A.; Boxer, M. B.; Hall, M. D.; Xia, M.; Guha, R.; Rohde, J. M. Canvass: A Crowd-Sourced, Natural-Product Screening Library for Exploring Biological Space. ACS Cent. Sci. 2018, 4 (12), 1727-1741. https://doi.org/10.1021/acscentsci.8b00747.

(14) Rozengart, E. V; Basova, N. E. Ammonium Compounds with Localized and Delocalized Charge as Reversible Inhibitors of Cholinesterases of Different Origin. J. Evol. Biochem. Physiol. 2001, 37 (6), 604-610 https://doi.org/10.1023/A:1014414126143.

(15) Knight, B. J.; Tolchin, Z. A.; Smith, J. M. A Predictive Model for Additions to N-Alkyl Pyridiniums. Chem. Commun. 2021, 57 (21), 2693-2696. https://doi.org/10.1039/D1CC00056J.

(16) Ma, S.; Ni, B. Double Ring-Closing Metathesis Reaction of Nitrogen-Containing Tetraenes: Efficient Construction of Bicyclic Alkaloid Skeletons and Synthetic Application to Four Stereoisomers of Lupinine and Their Derivatives. Chem. - A Eur. $\begin{array}{lllll}J & \mathbf{2 0 0 4}, \quad 10 & \text { (13), }\end{array}$ https://doi.org/10.1002/chem.200305581.

(17) Noël, R.; Fargeau-Bellassoued, M.-C.; Vanucci-Bacqué, C.; Lhommet, G. No Title. Synthesis (Stuttg). 2008, 12, 1948.

(18) Agami, C.; Dechoux, L.; Hebbe, S.; Ménard, C. No Title. Tetrahedron 2004, 60, 5433.

(19) Ledoux, S.; Marchalant, E.; Célérier, J.-P.; Lhommet, G. No Title. Tetrahedron Lett. 2001, 42, 5397.

(20) Mangeney, P.; Hamon, L.; Raussou, S.; Urbain, N.; Alexakis, A. No Title. Tetrahedron 1998, 54, 10349.

(21) Morley, C.; Knight, D. W.; Share, A. C. No Title. J. Chem. Soc., Perkin Trans. 1 1994, 20, 2903.

(22) Hua, D. H.; Miao, S. W.; Bravo, A. A.; Takemoto, D. J. No Title. Synthesis (Stuttg). 1991, 11, 970.

(23) Airiau, E.; Spangenberg, T.; Girard, N.; Breit, B.; Mann, A. Short Access to $(+)$-Lupinine and $(+)$-Epiquinamide via Double Hydroformylation. Org. Lett. 2010, 12 (3), 528-531. https://doi.org/10.1021/o1902718q.
Charette, A. B.; Grenon, M.; Lemire, A.; Pourashraf, M.; Martel, J. Practical and Highly Regio- and Stereoselective Synthesis of 2Substituted Dihydropyridines and Piperidines: Application to the Synthesis of (-)-Coniine. J. Am. Chem. Soc. 2001, 123 (47), 11829-11830. https://doi.org/10.1021/ja017136x.

Sun, Z.; Yu, S.; Ding, Z.; Ma, D. Enantioselective Addition of Activated Terminal Alkynes to 1-Acylpyridinium Salts Catalyzed by $\mathrm{Cu}-\mathrm{Bis}(\mathrm{Oxazoline})$ Complexes. J. Am. Chem. Soc. 2007, 129 (30), 9300-9301. https://doi.org/10.1021/ja0734849.

Black, D. A.; Beveridge, R. E.; Arndtsen, B. A. CopperCatalyzed Coupling of Pyridines and Quinolines with Alkynes: A One-Step, Asymmetric Route to Functionalized Heterocycles. J. Org. Chem. 2008, 73 (5), 1906-1910. https://doi.org/10.1021/jo702293h.

Kou, X.; Zhao, Q.; Guan, Z.-H. Copper-Catalyzed Asymmetric Dearomative Alkynylation of Isoquinolines. Org. Chem. Front. 2020, 7 (6), 829-833. https://doi.org/10.1039/D0QO00041H.

Pappoppula, M.; Cardoso, F. S. P.; Garrett, B. O.; Aponick, A. Enantioselective Copper-Catalyzed Quinoline Alkynylation. Angew. Chemie Int. Ed. 2015, 54 (50), 15202-15206. https://doi.org/https://doi.org/10.1002/anie.201507848.

A. Bull, J.; J. Mousseau, J.; Pelletier, G.; B. Charette, A. Synthesis of Pyridine and Dihydropyridine Derivatives by Regioand Stereoselective Addition to N-Activated Pyridines. Chem. $\begin{array}{llll}\text { Rev. 2012, } & 112 & \text { (5), 2642-2713. }\end{array}$ https://doi.org/10.1021/cr200251d.

Ding, Q.; Zhou, X.; Fan, R. Recent Advances in Dearomatization of Heteroaromatic Compounds. Org. Biomol. Chem. 2014, 12 (27), 4807-4815. https://doi.org/10.1039/C4OB00371C.

Bertuzzi, G.; Bernardi, L.; Fochi, M. Nucleophilic Dearomatization of Activated Pyridines. Catalysts . 2018. https://doi.org/10.3390/catal8120632.

Sowmiah, S.; Esperança, J. M. S. S.; Rebelo, L. P. N.; Afonso, C. A. M. Pyridinium Salts: From Synthesis to Reactivity and Applications. Org. Chem. Front. 2018, 5 (3), 453-493. https://doi.org/10.1039/C7QO00836H.

Hashimoto, S.; Yamada, S.; Koga, K. Asymmetric Syntheses Using Tert-Leucine. 1. An Asymmetric Synthesis of .Beta.Substituted Aldehydes via 1,4-Addition of Grignard Reagents to Chiral .Alpha.,.Beta.-Unsaturated Aldimines. J. Am. Chem. Soc. 1976, 98 (23), 7450-7452. https://doi.org/10.1021/ja00439a071. Yadav, J. S.; Reddy, B. V. S.; Sreenivas, M.; Sathaiah, K. Facile Addition of Alkynes to Aza-Aromatic Systems: A New Protocol for the Preparation of 2-Alkynyl-1,2-Dihydroquinolines. Tetrahedron Lett. 2005, 46 (51), 8905-8908. https://doi.org/https://doi.org/10.1016/j.tetlet.2005.10.101.

Yamaguchi, R.; Hata, E.; Utimoto, K. Regio- and Chemoselective Addition of Alkynyltin Reagents to the 2-Position of 3Acylpyridines Activated by Methyl Chloroformate: Selective Synthesis of 2,3-Disubstituted 1,2-Dihydropyridines. Tetrahedron Lett. 1988, 29 (15), 1785-1788. https://doi.org/https://doi.org/10.1016/S0040-4039(00)82043-2. Yamaguchi, R.; Moriyasu, M.; Yoshioka, M.; Kawanisi, M. Reaction of Allylic Tin Reagents with Nitrogen Heteroaromatics Activated by Alkyl Chloroformates: Regioselective Synthesis of .Alpha.-Allylated 1,2-Dihydropyridines and Change of the Regioselectivity Depending on Methyl Substituents at the Allylic Moiety. J. Org. Chem. 1988, 53 (15), 3507-3512. https://doi.org/10.1021/jo00250a018.

Itoh, T.; Hasegawa, H.; Nagata, K.; Okada, M.; Ohsawa, A. A New Entry to the Ethynylation of Azaaromatics Using Bis(Tributylstannyl)Acetylene in the Presence of Alkyl Chloroformate. Tetrahedron 1994, 50 (46), 13089-13100. https://doi.org/https://doi.org/10.1016/S0040-4020(01)89318-2.

Yamada, S.; Toshimitsu, A.; Takahashi, Y. A Significant Substituent Effect on the Regioselectivity in Addition of Alkynes to 3-Substituted Pyridines. Tetrahedron 2009, 65 (11), 2329 2333. https://doi.org/https://doi.org/10.1016/j.tet.2009.01.022.

Talele, T. T. The "Cyclopropyl Fragment" Is a Versatile Player That Frequently Appears in Preclinical/Clinical Drug Molecules. J. Med. Chem. 2016, 59 (19), 8712-8756. https://doi.org/10.1021/acs.jmedchem.6b00472.

Lee, H. J.; Zhang, W.; Zhang, D.; Yang, Y.; Liu, B.; Barker, E. L.; Buhman, K. K.; Slipchenko, L. V; Dai, M.; Cheng, J.-X. Assessing Cholesterol Storage in Live Cells and C. Elegans by 
Stimulated Raman Scattering Imaging of Phenyl-Diyne Cholesterol. Sci. Rep. 2015, 5 (1), 7930. https://doi.org/10.1038/srep07930.

(41) Meyers, A. I. Chiral Oxazolines and Their Legacy in Asymmetric Carbon-Carbon Bond-Forming Reactions. J. Org. Chem. 2005, 70 (16), 6137-6151. https://doi.org/10.1021/jo050470h.

(42) Watanabe, R.; Mizoguchi, H.; Oikawa, H.; Ohashi, H.; Watashi, K.; Oguri, H. Stereo-Controlled Synthesis of Functionalized Tetrahydropyridines Based on the Cyanomethylation of 1,6Dihydropyridines and Generation of Anti-Hepatitis C Virus Agents. Bioorg. Med. Chem. 2017, 25 (11), 2851-2855. https://doi.org/https://doi.org/10.1016/j.bmc.2017.03.011.
(43) Di Pietro, O.; Alencar, N.; Esteban, G.; Viayna, E.; Szałaj, N.; Vázquez, J.; Juárez-Jiménez, J.; Sola, I.; Pérez, B.; Solé, M.; Unzeta, M.; Muñoz-Torrero, D.; Luque, F. J. Design, Synthesis and Biological Evaluation of N-Methyl-N-[(1,2,3-Triazol-4Y1)Alkyl]Propargylamines as Novel Monoamine Oxidase B Inhibitors. Bioorg. Med. Chem. 2016, 24 (20), 4835-4854. https://doi.org/https://doi.org/10.1016/j.bmc.2016.06.045.

(44) Al-awar, R. S.; Joseph, S. P.; Comins, D. L. Conversion of NAcyl-2,3-Dihydro-4-Pyridones to 4-Chloro-1,2Dihydropyridines Using the Vilsmeier Reagent. Synthesis of (-)Coniine and ( \pm )-Lupinine. J. Org. Chem. 1993, 58 (27), 77327739. https://doi.org/10.1021/jo00079a018. 